Harrison; L. W. (1930). "Health and Empire." British Social Hygiene Council, London. Vol. 5, p. 169.

Hinrichsen, Josephine (1943). Amer. J. Syph., 27, 319.

Jeans, P. C., and Cooke, J. V. (1930). "Prepubescent Syphilis." p. 67. Appleton, New York.

Kemp, J. E., and Moore, J. E. (1922). Arch. Derm. Syph., Chicago, 6, 57.

McDonald, S., Jr. (1932). Brit. J. vener. Dis., 8, 263. (1934). Ibid., 10, 183.

Melchior, L. (1904). Dissertation. Quoted by Hinrichsen.

Nabarro, D. N. (1927). Lancet, 2, 692.

Osler, William (1917). Trans. med. Soc. Lond., 40, 290.

Payne, R. T. (1940). Brit. med. J., 1, 287.

Rach, E., and Wiesner, R. (1907). Wien. klin. Wschr., 20,521 .
Rose, Elizabeth K., Gyorgy, P., and Ingraham, N. R., Jr. (1948). "Recent Advances in the Study of Venereal Diseases. A Symposium." U.S. publ. Hlth Service, p. 247.

Smith-Wilson, Marjorie (1930). " Health and Empire." British Social Hygiene Council, London. Vol. 5, p. 179.

Stefano, S. de (1920). Pediatria, 28, 992.

Stobie, W. (1921). Quart. J. Med., 15, 26.

Turnbull, H. M. (1915). I Ibid., 8, 224.

Warthin, A. S. (1911). Amer. J. med. Sci., 141, 398. (1916). Ibid., 152, 508.

_ , and Snyder, E. J. (1912). J. Amer. med. Ass., 58, 689.

Wattie, Nora I. (1944). Brit. J. vener. Dis., 20, 61.

Wiesner, R. (1905). Z Zbl. allg. Path. path. Anat., 16, 822.

\title{
DISCUSSION ON CONGENITAL SYPHILIS
}

Dr. Mary Shaw said she had been taught that in these cases a routine $x$-ray picture of the lower end of the femur should be taken, but Dr. Nabarro apparently found the tibia more frequently involved; perhaps it would be better to radiograph the tibia than the femur.

Dr. Forgan said that between the two wars the incidence of positive serological reactions in expectant mothers became so low that the London County Council for a time abandoned routine Wassermann examinations at antenatal clinics. The fact that penicillin was so effective in the treatment of syphilis in pregnant women ought to mean a further reduction in the number of cases of congenital syphilis : but it was to be hoped that there would, in future, be no relaxation of routine blood examinations in pregnancy.

DR. Hamilton Wilkie (the President) thought it would be interesting to have Dr. Nabarro's opinion on the case in which a child was suspected of congenital syphilis but the mother had a negative Wassermann. There might be evidence later that she also had syphilis. It was not uncommon for the diagnosis in children with congenital syphilis to be missed because the mother had not a positive Wassermann reaction.

DR. R. R. Willcox also drew attention to the not uncommon perplexing finding of the sero-negative mother of the child with congenital syphilis. Only recently he had been consulted by an anxious mother because her husband had died of aortitis. Over a period. of three months he tested her blood on three occasions, each time with negative results, and chest radiograph and cerebrospinal fluid examinations were also negative. He did not treat her, but kept her under observation. He was distressed some weeks later to find that her twenty-year-old daughter was receiving treatment for an undoubted congenital infection. The mother was suffering from "burnt-out" syphilis.

DR. S. M. LAIRD thought Dr. Nabarro's opening remarks regarding incidence were of great interest.
While no doubt the recorded incidence of congenital syphilis in this country had fallen, this should not encourage complacency. The rate of fall had been considerably less than in other countries. He remembered being in Stockholm in 1939 and being taken to see the Welander Home, which had been established for the institutional care of congenital syphilitic children. His host apologized for the fact that he could not show him any cases, and added that congenital syphilis had become almost negligible in Sweden.

From his own experience in this country Dr. Laird felt certain that congenital syphilis was seen in rural communities much more than in big cities. He referred not to congenital syphilis in infancy, but to the late manifestations of congenital syphilis. Suffolk, where he practised now, provided material for those interested in congenital syphilis. There they saw cases some of which were obvious clinically and which had been referred from other departments because of nerve deafness, keratitis, etc. ; but many cases came to him as a result of antenatal blood-testing or the testing of potential blood donors, and a number of these had a positive blood test and were examples not of acquired but of congenital syphilis. Some of these people in their thirties or forties had stigmata of congenital infection.

On that point there was a warning which he would like to utter. They had heard Dr. Nabarro frequently, and he lost no opportunity of pressing his plea for antenatal blood-testing. But that was not the whole difficulty. In his area until June 1947 the antenatal service took blood for Wassermann and Kahn tests, and the blood went to a laboratory which was doing all the venereal disease serology for that area. In the middle of June 1947 the blood transfusion service took over and insisted that in pregnant mothers the $\mathrm{Rh}$ factor must be estimated and that a routine Kahn should also be done. This was awkward because the antenatal services said, "We cannot very well take two specimens of blood "; and so the previous laboratory ceased to function, and the routine antenatal blood specimens now went to a laboratory which estimated the Rh factor 
and did a routine Kahn. After some months' experience it became quite evident that the Kahn was very insensitive, and cases were being lost because the antenatal Kahn test was being done at a laboratory which was not interested in the venereal disease aspect, and the technique appeared to leave something to be desired.

There were certain questions which arose out of the paper. He had a very interesting case almost three years ago-a mother who gave birth to twins, one twin, a girl, being a congenital syphilitic, and the other twin, a boy, being healthy. He had been able to follow them for almost three years and there was no question that the girl was infected and the boy had escaped. Was that experience rare or had Dr. Nabarro met with other examples?

Dr. Laird asked how early after birth the typical Wimberger's sign was to be seen in the head of the tibia.

To his final question he did not expect a very definite answer. How long must one go on treating the congenital syphilitic? He used to believe that after the age of 25 it was reasonable to stop treatment, but during the last three years he had seen two patients whom he had assured that they did not need any further treatment because they were over 30 at the time, yet later, they developed interstitial keratitis.

Dr. Oliver raised the question of the importance of contraception in the prevention of congenital syphilis. Now that penicillin, when given to the mother, achieved a 100 per cent. cure of the infant, were they entitled to say to syphilitic parents, "You can have children," or must they say, "No, you must use contraceptives until we advise you otherwise"? This was an important question. In Ireland the use of contraceptives was illegal. It would do a great deal of good if an official statement could be made by a Society such as theirs. In Dublin' congenital syphilitics were very numerous; and the Rotunda Hospital figures for positive maternal Wassermann tests was between 4 and 6 per cent.

Had Dr. Nabarro any record of the percentage of congenital syphilitics born to mothers with negative Wassermanns? That figure would be illuminating.

DR. MCELligotr said that the figures which Dr. Nabarro had quoted showing the decrease in the number of deaths from congenital syphilis and the decrease of reported cases undoubtedly reflected a high degree of watchful antenatal care. That it was not watchful enough he agreed. He would like to see blood tests carried out on every expectant mother, and now, with the popularity of tests for the Rh factor, he hoped that half the blood taken would be diverted to the serologist.

He was delighted to hear Dr. Nabarro praise bismuth. It was an efficient and safe drug, and when he looked over his records at St. Mary's Hospital and saw the number of cases of syphilis, early, late, and congenital, which for one reason or another had been treated mainly with bismuth, he was surprised to note how good the results had been. Bismuth still continued to hold its place as an adjuvant to penicillin.

With regard to Dr. Laird's comparison of this country with Sweden, the obvious retort was that Sweden had not fought two wars in twenty-five years. Its people had for long had a health sense well above average. Also its density of population was far less than ours.

Dr. McElligott would agree that there were probably some patients treated in special hospitals who did not figure in our returns, and he hoped that something would shortly be done to rectify this omission.
With regard to antenatal penicillin therapy, there seemed to be little doubt that in the majority of cases a week's penicillin would probably be adequate preventive treatment for the unborn child. He would, however, agree that the advisability of this procedure in all cases, especially those in which the maternal infection is known to be of comparatively recent date, is open to criticism. So long as relapse is possible in the mother, it is also possible for the infection to be retransmitted to her unborn child, and in order to be certain that this will not happen it is logical that treatment be continued to the final day.

MR. A. J. KING referred to the subject of cardiovascular involvement in congenital syphilis and wondered whether Dr. Nabarro's suspicion that aortitis and its complications were much commoner than was generally supposed was well founded. Undoubtedly there were authentic cases in which such involvement did occur. On the other hand, a fair number of patients were seen in later life suffering from congenital syphilis and it was extremely uncommon to find any evidence of aortitis in them, although it could be assumed that most of them were carefully examined from this point of view.

Another matter on which he desired to hear more was interstitial keratitis, and whether it was possible by treatment to prevent the second eye from being involved. It was stated in the literature that various methods of treatment protected the second eye. There were many patients who had been observed for years in whom the second eye had not been involved, but some ophthalmologists with a lifetime of experience would say that if these cases were followed long enough sooner or later the second eye did become involved even after twenty or thirty years, whatever was done in the way of treatment. This brought him back to the point which Dr. Laird had mentioned, the question of the patient's being fully treated and yet developing interstitial keratitis after a lapse of years. Was it possible to prevent the development of such a condition in the future in the congenital syphilitic even with adequate and prolonged treatment?

DR. D. J. CAmpBell said that previous speakers had mentioned most of the difficulties which he himself had experienced. He was soothed by Dr. Nabarro's comments on the number of cases of undoubted congenital syphilis occurring where no clinical or serological proof of the disease could be found in either parent. The great problem was to know what to tell the parents, and how to get over the difficulty of the child's having to attend a venereal disease clinic.

Interstitial keratitis had been mentioned often enough to prove that it was one of the most difficult problems in the treatment of congenital syphilis. He had had two cases lately which had surprised and worried him until that evening. These were both women in the late thirties. From their records, which were well kept, they had full and prolonged treatment for no less than seven years in their late 'teens and early twenties. At the end of that time one girl had had a negative Wassermann reaction for several years; the other still had a weakly positive Wassermann. It was interesting that this second girl came to him in 1945, and again her Wassermann was weakly positive, the Kahn just showed a trace of flocculation. Now she had an acute interstitial keratitis of the eye that was affected seventeen or eighteen years ago.

They were agreed that they must not treat the Wassermann reaction : they must treat the patient. But there 
seemed to have been of recent years a great outburst of disappointment with their results regarding congenital syphilis.

One other point he wished to mention was that in congenital syphilis in what might be called a septicæmic or secondary stage in a newborn infant they should beware of penicillin therapy because they could kill the child by their enthusiasm for penicillin; this was far more likely than death from syphilis itself. A conservative approach to the treatment of a child in that disseminated stage was wiser than a robust attack with penicillin.

DR. JEAN MORTON said that the question of interstitial keratitis recurring or occurring for the first time had interested her very much. She was not sure that they were right in assuming that the interstitial keratitis occurring after treatment was necessarily of syphilitic origin. In a case of tuberculous joint very frequently there was a history of a definite injury. Could there not be some factor, other than syphilis, to account for the occurrence of interstitial keratitis in a case of welltreated congenital syphilis?

DR. NABARRo, in reply, said he had seen many cases where the Wassermann test was negative when a positive result had been expected. One must always bear in mind the fact that even an active case of syphilis with secondary manifestations might give a negative Wassermann reaction. A mother with a negative blood test might bear a child with congenital syphilis and even with a positive Wassermann reaction. He could recall the interesting case of a congenitally syphilitic father who apparently passed the infection on to his child without any discoverable sign or symptom of the disease in the mother-even to a negative Wassermann reaction for seventeen years.

Dr. Mary Shaw had asked about the relative value in diagnosis of radiographs of the femur and tibia. Before the war at the Hospital for Sick Children, they always examined all four limbs. If he were restricted to a radiograph of one bone he would prefer one of the tibia, which in his experience was more often and more markedly affected than any other bone. In the literature authorities had cited other bones as being most commonly or severely affected : distal end of humerus ; distal ends of radius and ulna ; distal end of the femur. All four limbs should be radiographed if possible and they should be so held that the tibia did not overlap the fibula and that the forearm bones were supinated.

He agreed with Dr. Forgan that it was sometimes difficult to obtain the co-operation of authorities and, from his own experience he could add, of fellow practitioners. This was to be regretted, for all should realize that our aims were to do the best for our patients and to advance knowledge, and nothing should be allowed to hinder the fulfilment of those aims.

He supported Dr. Forgan's view that congenital syphilis was a preventible disease and that it should not exist. The problem appeared to be how to discover all the positively-reacting pregnant mothers, for there were not sufficient trained pathologists and technicians in the country to carry out the tests. A scheme should certainly be evolved for the testing and, where necessary, the treating of expectant mothers, for its cost would pay a dividend in the eradication of congenital syphilis and in the cure of the disease in the mothers.

$\mathrm{He}$ had not, so far as he could recall, seen a case of syphilis passed on from a child to an adult, but they were not at all uncommon in the past and Sir Frederick Still's article on congenital syphilis, in Power and Murphy's "System of Syphilis," concluded with the account of a grandmother who contracted the disease from her grandchild, as did also a brother of seven and a sister of twelve.

The points of interest in the case quoted by Dr. Willcox were : (1) The father's aortitis was presumably syphilitic and probably of acquired origin. To ascertain whether the syphilis could have been of congenital origin would have necessitated considerable anamnestic inquiry which might, even if successful, not furnish a convincing result. (2) The mother's negative blood serology presented two problems, both today insoluble. Had the blood ever been positive and, if not, could this state of affairs have resulted from the father's having been a congenital syphilitic-a position similar to that in the case he (Dr. Nabarro) had just referred to ? On the other hand the mother's blood might have shown a positive Wassermann when the daughter was born and for some years afterwards, and might now by efflux of time have become negative.

He agreed that we should not be complacent about the reduction in the incidence of congenital syphilis in this country; he thought that on the contrary there should be an extension of antenatal blood testing and that the test should be carried out by an approved technique. He was pleased to have Dr. Laird's confirmation of the not infrequent occurrence of symptoms and signs of congenital syphilis in patients in their thirties and forties. With regard to the infection in twins: with binovular twins it was quite possible for one infant to be infected and the other to escape the infection, as in Dr. Laird's case. Such instances were not very rare and several had been recorded in the literature. He himself had seen two such cases.

The characteristic lesion at the upper and inner aspect of the tibia-the so-called Wimberger's sign-he had found at the necropsy of a child of six weeks. It might be present at an earlier date, possibly even in utero, but on this point he had no information.

How long should a congenitally syphilitic patient be treated? This was a difficult question to answer. It depended upon the age at which treatment was begun and also upon the amount of treatment given. Before a patient was discharged one should always examine the spinal fluid and one should not cease treatment until the fluid had become normal. Even after all this treatment and care it was conceivable that a patient might develop interstitial keratitis, but he himself had not come across such a case.

In reply to the question about the necessity for advising contraception in the prevention of congenital syphilis, it would appear to follow from American observations that penicillin, given as described in his paper, could be relied upon to protect the fœtus from syphilis; so that provided treatment could be started by the fifth month and a subsequent Wassermann reaction was negative or showed a marked fall in titre, it should be safe to dispense with contraceptives. In the event, however, of a blood test being still strongly positive, a repeat course of penicillin could be given.

The figures for congenital syphilitic children born to mothers with negative Wassermann reactions must be small for any individual observer. In his own experience, of 240 syphilitic children under 2 years of age only 3 , or 1.25 per cent., had mothers with a negative blood test. Jeans and Cooke in 383 families found 28 children under 2 , or $7 \cdot 3$ per cent., whose mothers had negative Wassermann reactions. In the case of children over the age of 2 years, the corresponding figures would 
be 40 mothers with negative reactions out of 213 , or 18.8 per cent. (Nabarro); 64 out of 264 , or 24.2 per cent. (Jeans and Cooke), the explanation being that in the case of the older children the mothers' Wassermann reactions had become weaker or negative by efflux of time.

Dr. McElligott had made an interesting observation about cases during the late war which broke down under training. He (Dr. Nabarro) had written a paper in the Lancet (March 1943) on "Unrecognized Congenital Syphilis," which might answer some of the questions raised. He believed that people whose latent congenital syphilis was revealed during their training in the last war got it from their fathers who had contracted the disease during the earlier war and were given sufficient treatment to render them non-infective, or only slightly infective, for a time, so that the child's syphilis lay dormant and only manifested itself years afterwards when the man broke down under training. He had seen several such cases, also congenital mothers who had been similarly infected by insufficiently-treated fathers.

Concerning the figures he had shown on the screen and commented upon by Dr. McElligott, he was certain that many cases were missed not only by general practitioners but also by specialists for weeks and months and sometimes for years. At other children's hospitals than Great Ormond Street and at many of the smaller general hospitals there were no venereal diseases clinics and their cases would in consequence not be reported. This would account for a considerable number of unrecorded cases, which resulted in a serious underestimate of the morbidity and mortality from congenital syphilis.

He was holding no brief for the penicillin treatment of congenital syphilis and of syphilitic expectant mothers, but had given the latest reports from American sources. He would certainly like to see similar investigations carried out in this country, in order that, having used our own methods of observation and reporting, we might be able to assess the results and to compare them with those obtained by other investigators.

He was pleased to hear that Dr. McElligott had formed as high an opinion as he himself had done of the value of bismuth for the treatment of syphilis. Several infants with positive cerebrospinal fluids had been rendered Wassermann-negative in both blood and fluid by one course of twelve injections of bismuth oxychloride.

Concerning the subject of cardiovascular involvement in congenital syphilis, he knew that the association of the two conditions was not usually regarded as being frequent. His contention was that the possibility of the acknowledged syphilitic origin of many cardiovascular lesions being congenital rather than acquired was rarely entertained by practitioners. He believed that if congenital syphilis as a possible cause of cardioaortic disease were borne in mind and were carefully and impartially looked for, it would more frequently be found to be an originator of the condition than if the subject were approached in a sceptical spirit. The anamnesis was important in tracking down congenital syphilis in grown-ups, for the Wassermann reaction might frequently be found to be negative in the adult congenital syphilitic.

Several members, including $\mathrm{Mr}$. King, had enquired about interstitial keratitis, which was certainly one of the most difficult of the unsolved problems in syphilology. There was no doubt that in a certain number of cases, possibly 5 per cent., there was a history of trauma. In other cases it seemed to follow soon after starting injections for some other manifestation of late congenital syphilis, usually periostitis of the tibia or Clutton's knee. On that account some authorities regarded it not as a direct result of the syphilitic infection but as an allergic phenomenon. He had seen many cases in which prompt and energetic antisyphilitic treatment (in the pre-penicillin era) had cut short an attack and had apparently also prevented involvement of the second eye, but admittedly he had not been able to follow the patients for twenty or more years. He had seen children who had presumably been well treated; one child had had negative blood tests for eight years yet later had developed interstitial keratitis. He had had no experience with penicillin or pyretotherapy in the condition.

Dr. Campbell had also complained about the unfair behaviour of interstitial keratitis after patients had received what was considered to be a thorough course of treatment. It remained to be seen whether interstitial keratitis treated by the newer methods behaved similarly.

It was undoubtedly the case that one did come across patients with congenital syphilis whose parents gave no clinical or serological evidence of the infection. These cases were difficult to explain. As regards soothing the parents' feelings, it was possible to explain that the blood infection had been passed on from an ancestor without showing signs in the child's parents.

It was not difficult to kill by too energetic treatment infants who were born with the disease already manifest, and sometimes even those who might not have sickened until they were a few weeks old. He had himself done it with the arsenobenzole drugs on several occasions, and colleagues had confessed to having had similar experiences. In severe cases it was advisable to start the treatment with mercury or with minute doses of arsenic, bismuth, or penicillin.

Dr. Jean Morton's point about interstitial keratitis was an interesting one and, as had already been remarked, .it appeared as if some other factor might be present in these treated cases. This, in the present state of our ignorance, we suggest might be "allergy," but at the same time it did not tell us how to prevent keratitis. 